\title{
Virulence of Rhizoctonia oryzae on Wheat and Barley Cultivars from the Pacific Northwest
}

\author{
T. C. Paulitz, USDA-ARS, Root Disease and Biological Control Lab; and J. D. Smith and K. K. Kidwell, \\ Department of Crop and Soil Sciences, Washington State University, Pullman 99164-6420
}

\begin{abstract}
Paulitz, T. C., Smith, J. D., and Kidwell, K. K. 2003. Virulence of Rhizoctonia oryzae on wheat and barley cultivars from the Pacific Northwest. Plant Dis. 87:51-55.

Rhizoctonia oryzae (teleomorph $=$ Waitea circinata) causes sheath spot of rice and root rot of wheat and barley. R. oryzae commonly is isolated from barley, wheat, and pea plants in eastern Washington and Idaho. Eight representative isolates were tested for virulence on spring barley (Hordeum vulgare cv. Baronesse), soft white winter wheat (Triticum aestivum cv. Madsen), and hard red spring wheat (cv. Scarlet) planted in natural soil in the greenhouse and maintained at $16^{\circ} \mathrm{C}$. All isolates caused significant reduction of emergence in barley, but only seven of the eight isolates and one of the eight isolates reduced emergence of winter wheat and spring wheat, respectively. All isolates caused significant stunting and reduction in the number of seminal roots, root length, and number of root tips on wheat and barley. Some isolates also reduced the frequency of fine secondary roots, resulting in a reduction of the average root diameter. Spring barley was more susceptible to $R$. oryzae than winter or spring wheat. The main effects of both cultivar and isolate were significant, and there was a significant isolatecultivar interaction. $R$. oryzae isolate 80042 was the most virulent on barley, whereas $R$. oryzae isolate 801387 was the most virulent on wheat. The two isolates from pea were intermediate in virulence on wheat and barley. When screening germ plasm for potential resistance, isolates exhibiting the maximum virulence for each host should be used.
\end{abstract}

Additional keywords: Hordeum vulgare, Rhizoctonia root rot, Triticum aestivum, Waitea circinata

Rhizoctonia oryzae Ryker \& Gooch, the causal agent of sheath spot of rice, was first described in Louisiana in 1937 (16). This multinucleate Rhizoctonia sp. is closely related to $R$. zeae, which causes rot of corn (21) and turf grass patch diseases $(3,7,8,9)$. The teleomorph of $R$. oryzae is Waitea circinata Warcup \& Talbot, first isolated from soil in Australia in 1962 (22). $R$. oryzae and $R$. zeae were linked to their teleomorphs by Oniki et al. (12), who found two separate anastomosis groups for the anamorphs, named WAG-O and WAG$\mathrm{Z}$, respectively. W. circinata also causes root rot of subterranean clover in Australia $(25,26)$, damping-off of tobacco (15), and stunting of barley in the United Kingdom (1), Alaska (6), and Turkey (4).

Corresponding author: T. C. Paulitz

E-mail: paulitz@wsu.edu

Funding for this project was provided by a USDACREES Biotechnology Risk Assessment Grant, the O. A. Vogel Fund and the College of Agriculture and Home Economics at Washington State University.

Accepted for publication 25 August 2002.

Publication no. D-2002-1114-01R

This article is in the public domain and not copyrightable. It may be freely reprinted with customary crediting of the source. The American Phytopathological Society, 2003.
The first record of $R$. oryzae in the Pacific Northwest was reported in 1952 (19), but Rhizoctonia root rot was not considered to be a problem on cereals until the discovery of root rot and patch disease in 1984, caused by $R$. solani AG-8 (23). Based on a survey conducted in the late 1980 s, $R$. oryzae made up $45 \%$ of isolates collected from 45 wheat and barley fields in Oregon, Washington, and Idaho, which was a higher frequency than $R$. solani AG8 (11). $R$. oryzae was moderately pathogenic to wheat and barley at $20^{\circ} \mathrm{C}$, but nonpathogenic or mildly pathogenic at $10^{\circ} \mathrm{C}$. Conversely, $R$. solani $\mathrm{AG}-8$ was highly pathogenic at $10^{\circ} \mathrm{C}$, but mildly pathogenic at $20^{\circ} \mathrm{C}$. A later greenhouse study in Oregon (17) also concluded that $R$. oryzae did not cause root rot of wheat in natural soil with day and night temperatures of 23 and $11^{\circ} \mathrm{C}$ or 19 and $6^{\circ} \mathrm{C}$, respectively, and did not limit yield in field experiments with winter wheat. However, Mazzola et al. (10) found that 12 of 19 isolates reduced emergence and root biomass of wheat at $12^{\circ} \mathrm{C}$.

$R$. oryzae comprised $69 \%$ of the 274 isolates of Rhizoctonia obtained in a survey conducted in eastern Washington in 2000 to 2001 , and up to $100 \%$ of the isolates of Rhizoctonia in some fields (14). Despite the prevalence of $R$. oryzae in eastern Washington, little is known about its relative virulence to the three major cereal grains grown in this area: spring barley, spring wheat, and winter wheat. In addition, little is known about the variation in virulence within the population of the pathogen, and whether there is an isolatecultivar or plant type interaction. Except for Mazzola et al. (10), previous studies have only looked at one to three isolates of $R$. oryzae, typically on one host.

The objective of this work was to examine the variation in virulence among isolates of $R$. oryzae on representative cultivars of winter wheat, spring wheat, and spring barley in the greenhouse. Virulence was quantified by measuring various shoot and root parameters on seedlings, including emergence, plant height, number of seminal roots, root length, number of root tips, and average root diameters.

\section{METHODS AND MATERIALS}

To assess the inherent variation in virulence of $R$. oryzae in eastern Washington, we selected eight representative isolates from barley, tall fescue, and pea (13). These isolates represented the variation in colony morphology among the hundreds of isolates of this species examined in culture. All isolates were collected in spring and summer 2001. These isolates were used to infest natural soil in greenhouse trials and planted with a popular cultivar of spring barley (Hordeum vulgare cv. Baronesse), hard red spring wheat (Triticum aestivum cv. Scarlet) (5), and soft white winter wheat (cv. Madsen).

The eight isolates of $R$. oryzae selected for virulence testing are listed in Table 1. Inoculum was produced in 1-liter Erlenmyer flasks filled with $250 \mathrm{ml}$ of oat grain soaked in water and autoclaved twice. The grain was inoculated with $101-\mathrm{cm}^{2}$ pieces from a 2-week-old potato dextrose agar (PDA) plate culture of each isolate. The flasks were shaken once each week, and the inoculum was harvested after 4 weeks. The colonized oat grain was spread out on clean paper, air dried, and stored at $4^{\circ} \mathrm{C}$. Tests for virulence were conducted in tapered plastic cones $(4 \mathrm{~cm}$ in diameter by $20.5 \mathrm{~cm}$ long; Ray Leach Cone-tainer, Canby, OR) with drain holes plugged with cotton. The bottom of the tubes were filled with $40 \mathrm{~cm}^{3}$ of medium vermiculite (Therm-O-Rock Industries, Inc., Chandler, AZ) and topped with $30 \mathrm{~cm}^{3}$ of natural Thatuna silt loam soil, collected from the Spillman Agronomy Farm of Washington State University, $5 \mathrm{~km}$ south of Pullman, 
WA. Two pathogen-colonized oat grains were placed in the middle of the soil layer. Controls consisted of tubes without added inoculum. There were seven replicate tubes for each isolate-cultivar treatment. Each tube was watered with $10 \mathrm{ml}$ of distilled water. The Cone-tainers suspended in their racks were covered with clear polyethylene to prevent the soil from drying and were incubated undisturbed for 5 days in a growth chamber set at $16^{\circ} \mathrm{C}, 95 \%$ humidity, and with a 12 -h photoperiod. After 5 days, two seeds of either spring wheat, winter wheat, or spring barley were placed on the soil surface, covered with $10 \mathrm{~cm}^{3}$ of noninfested natural Thatuna silt loam soil, and watered with $10 \mathrm{ml}$ of distilled water. An additional $10 \mathrm{ml}$ of distilled water was added to each Cone-tainer 10 days after planting. Treatments were arranged in a completely randomized design, and the trial was conducted three times. At the end of 2 weeks, the plants were washed free of soil and debris using a high-pressure stream of tap water. The number of emerged seedlings, plant height, and number of seminal roots were recorded. The roots were digitally scanned using a Hewitt-Packard ScanJet 5370C scanner and saved as TIF files. Root scans were analyzed using WinRhizo software (Regent Instruments Inc., Québec, Canada). This software calculated total root length, average root diameter, and number of root tips. The scans were manually adjusted to remove shadows, debris, and overlapping root segments before analysis. Trials 1 and 2 were analyzed by a different person than trial 3.

Data analysis. Data were analyzed using SAS (version 6.12; SAS, Inc., Cary, NC). Disease reactions of each cultivar to eight isolates of $R$. oryzae were analyzed as a randomized complete block design, with the three trials as blocks. Analysis of variance was conducted to test for significance of cultivar and isolate main effects, as well as to identify significant interactions among main effects (20). To determine if trials had similar variances and could be combined, the mean square error values were tested with an $F$ test. Least square means comparisons and least significant difference were utilized to determine significant differences between isolates and cultivars $(P<0.05)(20)$.

\section{RESULTS}

Except for average root diameter, there was a significant main effect of cultivar and isolate for all parameters measured. The cultivar-isolate interaction was significant for every parameter $(P<0.05)$, including average root diameter, indicating that the isolate effects were different for the different cultivars. There was also a significant trial-cultivar and trial-isolate interaction $(P<0.05)$ for all parameters measured by WinRhizo, except for root length. This was due to differences in trial 3 , where a different person made the root scan adjustments for overlapping roots, shadows, and debris before analysis. In general, the average root parameters and

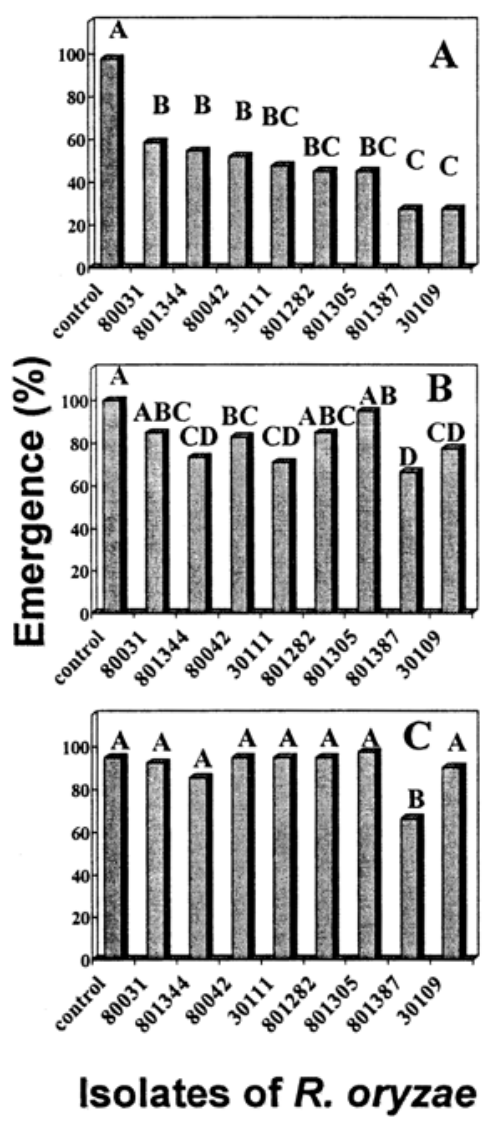

Fig. 1. Effect of isolates of Rhizoctonia oryzae on emergence of A, spring barley cv. Baronesse, B, soft white winter wheat $\mathrm{cv}$. Madsen, and $\mathbf{C}$, hard red spring wheat $\mathrm{cv}$. Scarlet. Treatments followed by the same letters are not significantly different, $P=0.05$, least significant difference test. variances measured by WinRhizo were higher in trial 3 ; therefore, the pooled results of trial 1 and 2 are presented for all WinRhizo data. For all other parameters, there was no significant trial effect and the results were pooled for the three trials.

Seedling emergence of spring barley (Fig. 1A) was significantly less with all eight isolates of $R$. oryzae, ranging from 27 to $58 \%$ compared with $>95 \%$ in the controls. Five out of eight isolates also resulted in lower percentages of emergence of winter wheat, although not to the same extent as barley (Fig. 1B). Emergence in inoculated treatments of winter wheat ranged from 66 to $85 \%$. Only isolate 801387 limited the emergence of spring

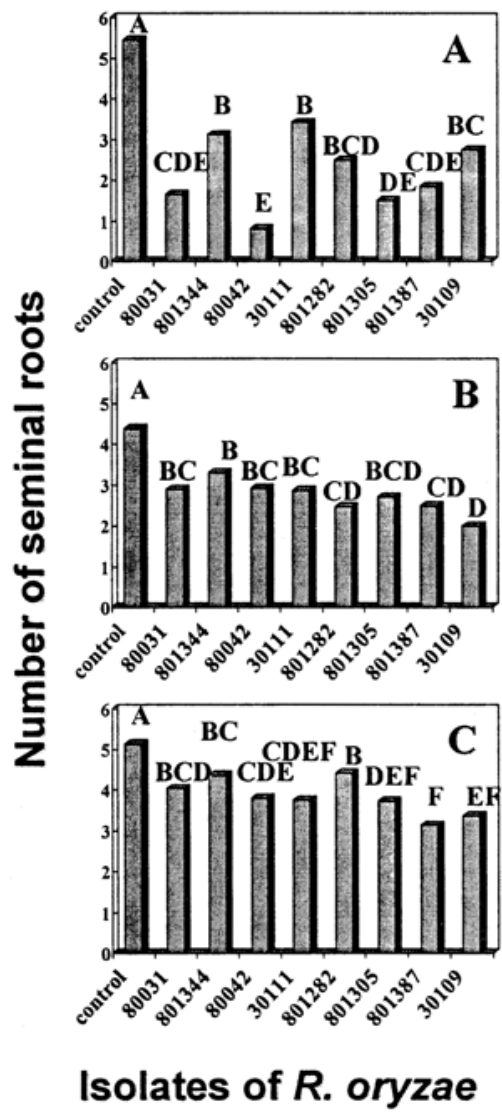

Fig. 2. Effect of isolates of Rhizoctonia oryzae on the number of seminal roots of $\mathbf{A}$, spring barley cv. Baronesse, B, soft white winter wheat cv. Madsen, and $\mathbf{C}$, hard red spring wheat cv. Scarlet. Treatments followed by the same letters are not significantly different, $P=$ 0.05 , least significant difference test.

Table 1. Rhizoctonia oryzae isolates tested for virulence on spring barley, spring wheat, and winter wheat in greenhouse evaluations

\begin{tabular}{lll}
\hline Isolate number & \multicolumn{1}{c}{ Collection location } & Host \\
\hline 030109 & ARS Palouse Conservation Farm, Pullman, WA & Tall fescue (Festuca arundinaceae) \\
030111 & Albion, WA & Pea (Pisum sativum) \\
80031 & Cunningham Agronomy Farm, Pullman, WA & Spring barley (Hordeum vulgare) \\
80042 & Cunningham Agronomy Farm, Pullman, WA & Spring barley \\
801282 & Garfield, WA & Spring barley \\
801305 & Garfield, WA & Spring barley \\
801344 & Lewiston, ID & Pea \\
801387 & Mockenema, WA & Spring barley \\
\hline
\end{tabular}


wheat (Fig. 1C), and this isolate was also the most virulent on winter wheat and spring barley.

All isolates of $R$. oryzae resulted in significantly fewer seminal roots of spring wheat, spring barley, and winter wheat, compared with controls (Fig. 2A-C). The greatest reductions in numbers of seminal roots occurred with spring barley where, in response to isolate 80042 , the number of seminal roots was only $15 \%$ of the number in the control (Fig. 2A). R. oryzae isolates were less virulent on winter wheat, and seminal root numbers in the inoculated treatments ranged from 45 to $75 \%$ of the control (Fig. 2B). The number of seminal roots on the spring wheat cultivar in response to $R$. oryzae was 61 to $86 \%$ of the number of roots in the control.

$R$. oryzae caused significant stunting of all three cultivars (Fig. 3A-C). Barley was the most sensitive, and plant heights were 37 to $68 \%$ less than the control plants. Isolate 80042 was the most damaging, resulting in plant heights only $32 \%$ of the height of the control. The height of inoculated winter wheat was 20 to $37 \%$ less than the control, and the height of inoculated spring wheat was 15 to $35 \%$ less than the control.

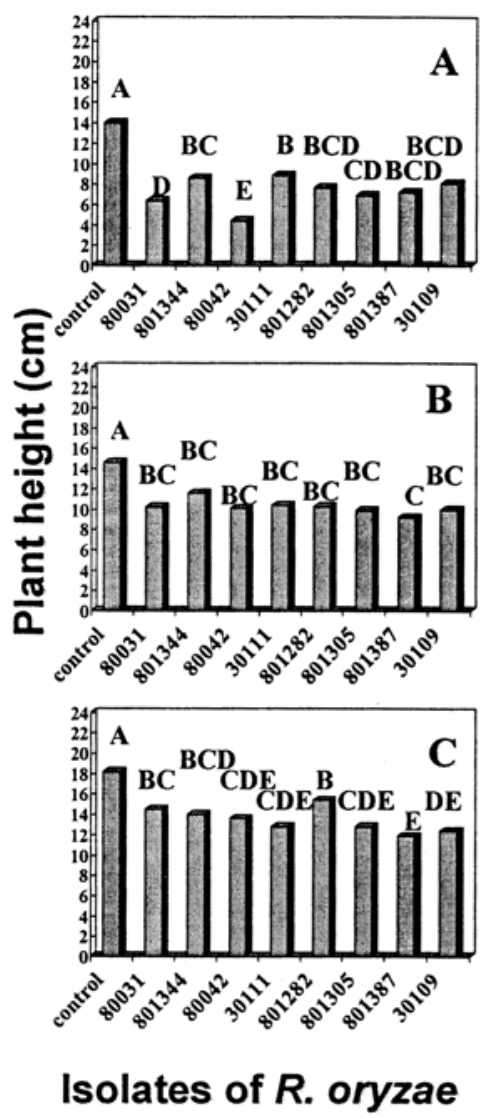

Fig. 3. Effect of isolates of Rhizoctonia oryzae on the height of A, spring barley cv. Baronesse, $\mathbf{B}$, soft white winter wheat cv. Madsen, and C, hard red spring wheat cv. Scarlet. Treatments followed by the same letters are not significantly different, $P=0.05$, least significant difference test.
All isolates restricted root length, with the greatest effects seen with spring barley, where root lengths were 65 to $93 \%$ less than the control (Fig. 4A). Lengths of inoculated winter wheat roots were 46 to $80 \%$ less than the controls (Fig. 4B), and the lengths of spring wheat roots were 34 to $71 \%$ less than the controls (Fig. 4C).

The average diameter of barley roots was higher than controls in treatments with four of the isolates, owing to fewer numbers of finer, secondary roots (Fig. 5A). Six isolates resulted in a larger average root diameter of winter wheat compared with the control (Fig. 5B) and six isolates resulted in a larger average root diameter of spring wheat (Fig. 5C)

All isolates of $R$. oryzae resulted in significantly fewer root tips in all plant types (Fig. 6A-C), with the greatest effect occurring on barley.

\section{DISCUSSION}

This study demonstrates that $R$. oryzae is pathogenic to wheat and barley in natural soils at $16^{\circ} \mathrm{C}$. It causes stunting, fewer seminal roots, and smaller root biomass, much like $R$. solani AG-8. However, in the field, the bare patch pattern of dead and stunted plants is not seen with $R$. oryzae;

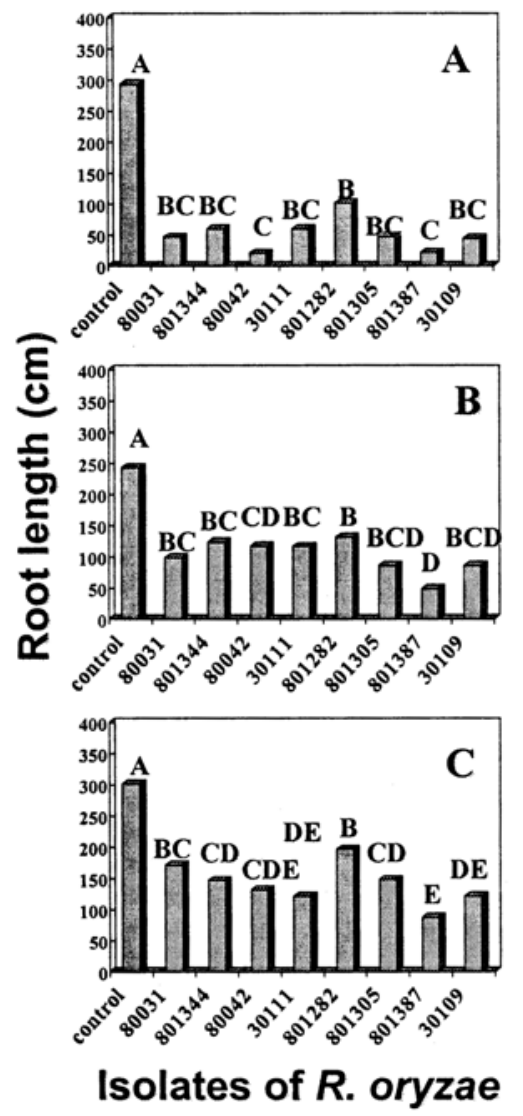

Fig. 4. Effect of isolates of Rhizoctonia oryzae on the total root length of $\mathbf{A}$, spring barley $\mathrm{cv}$. Baronesse, B, soft white winter wheat cv. Madsen, and C, hard red spring wheat cv. Scarlet. Treatments followed by the same letters are not significantly different, $P=0.05$, least significant difference test. rather, stands are uneven with some stunting and more open areas where weed infestations are often observed, especially in barley (T. C. Paulitz, unpublished data). These symptoms are consistent with a seed and root rotting pathogen attacking the seminal root system at an early stage of plant development. The effect of $R$. oryzae on root parameters was shown in some detail using the root scanning technology of WinRhizo, which is an improvement over root dry weight. The relative numbers of fine lateral and feeder roots, as deduced from average root diameter and root tip measurements, are very important for uptake of immobile nutrients such as phosphorus, and root pathogens can destroy or prevent the formation of these roots (2). Average root diameter was an integration of the diameters of the main axes along with all the smaller lateral roots. If these lateral roots are destroyed by the pathogen, or prevented from forming, the average root diameter will increase. $R$. oryzae resulted in less total root length and the number of root tips in most treatments. Although root analysis software improves the quantification of roots, it still requires some user interpretation to remove extraneous debris and shadows from the

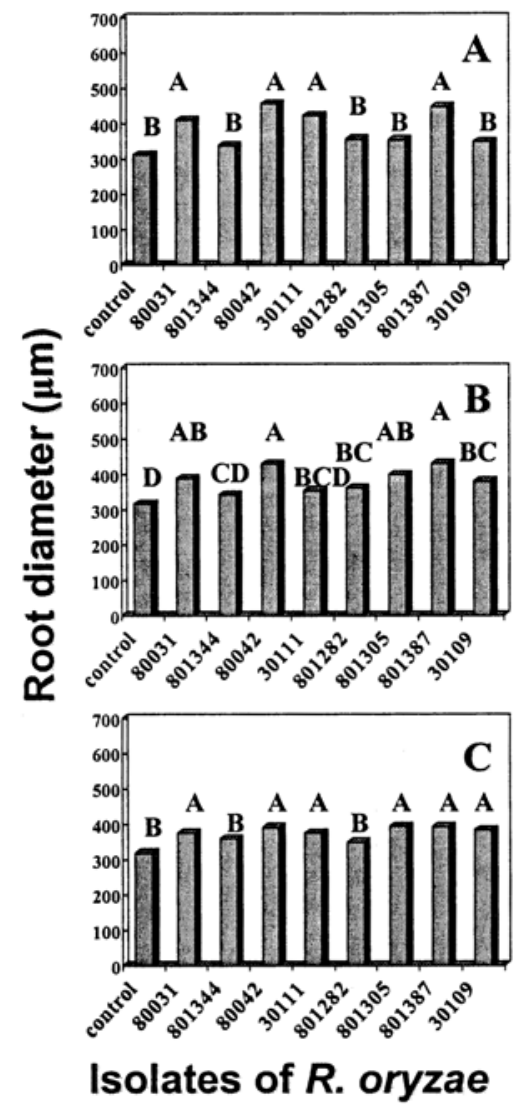

Fig. 5. Effect of isolates of Rhizoctonia oryzae on the average root diameter of $\mathbf{A}$, spring barley cv. Baronesse, B, soft white winter wheat cv. Madsen, and $\mathbf{C}$, hard red spring wheat cv. Scarlet. Treatments followed by the same letters are not significantly different, $P=$ 0.05 , least significant difference test. 
scans before analysis. In this work, we used a scanner that illuminated only from the bottom, which created shadows along the sides of the roots, especially the main root axes. The user who analyzed trials 1 and 2 spent much time removing these before analysis, and the variances in these two trials were much lower than in trial 3. In subsequent experiments, we used a scanner that illuminates from both the top and the bottom, and this eliminated the problem with shadows.

Unlike $R$. solani AG- $8, R$. oryzae also reduced emergence, especially on barley. Mazzola et al. (10) also showed that $R$. oryzae could reduce the emergence of wheat, but this is the first report showing a severe reduction of emergence of barley in natural soil. The increased susceptibility of barley compared with wheat has been observed in other experiments with $R$. oryzae (R. Davis, R. J. Cook, and T. C. Paulitz, unpublished data) and also with $R$. solani AG-8 (2). Ogoshi et al. (11) found a $63 \%$ reduction in plant height with $R$. oryzae on barley at $20^{\circ} \mathrm{C}$ in pasteurized soil, but only a $7 \%$ reduction with wheat. However, in natural soil, there were no significant differences. Rhizoctonia spp. often are more virulent in pasteurized soil, because

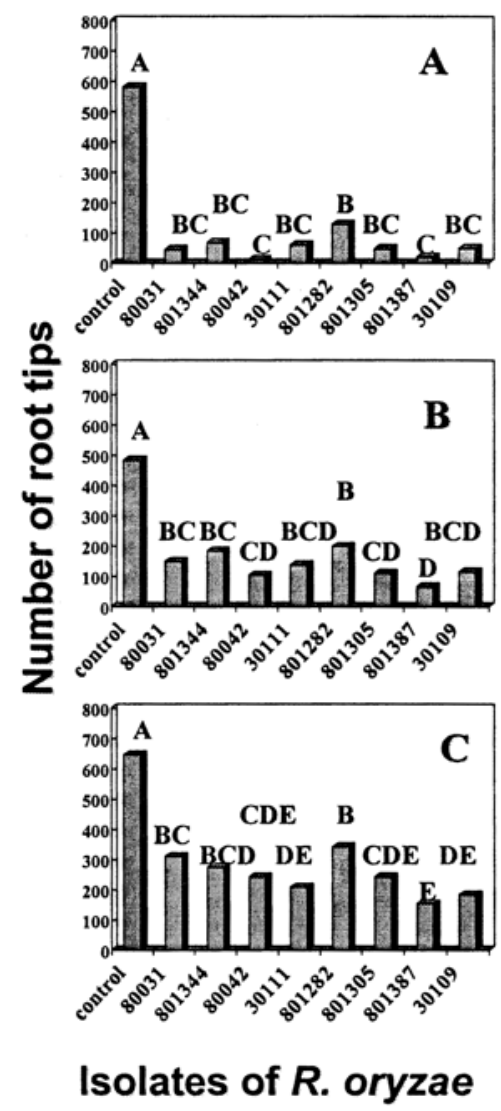

Fig. 6. Effect of isolates of Rhizoctonia oryzae on the total number of root tips of $\mathbf{A}$, spring barley cv. Baronesse, B, soft white winter wheat cv. Madsen, and $\mathbf{C}$, hard red spring wheat cv. Scarlet. Treatments followed by the same letters are not significantly different, $P=$ 0.05 , least significant difference test. of the lack of microbial competition. In this work, we specifically used natural soil to avoid this artifact. Another trend evident in all measurements was that the soft white winter wheat cv. Madsen was more sensitive to $R$. oryzae than the hard red spring wheat cv. Scarlet. However, more testing is required on additional winter and spring wheat cultivars to see if this finding can be extrapolated to entire market classes.

Temperature has been shown to play a major role in the virulence of $R$. oryzae. In our study, significant disease occurred in natural soil at $16^{\circ} \mathrm{C}$. Ogoshi et al. (11) reported that $R$. oryzae was pathogenic to wheat and barley at $20^{\circ} \mathrm{C}$ but not at $10^{\circ} \mathrm{C}$. Another study found no pathogenicity of $R$. oryzae at day and night temperatures of 23 and $11^{\circ} \mathrm{C}$ and 19 and $6^{\circ} \mathrm{C}$, but only at 27 and $16^{\circ} \mathrm{C}$ (17). In a study conducted in potting mix, $R$. oryzae was pathogenic at 18 and $26^{\circ} \mathrm{C}$, but not at $12^{\circ} \mathrm{C}$ (1). Our results indicate that $R$. oryzae can be pathogenic at temperatures below $18^{\circ} \mathrm{C}$, similar to the results of Mazzola et al. (10), who showed pathogenicity at both 12 and $20^{\circ} \mathrm{C}$. When winter wheat is emerging in the fall, the average soil temperature at a 5-cm soil depth in Pullman WA in October and November 1998 was 8.3 and $4.2^{\circ} \mathrm{C}$, respectively. During April and May, when spring wheat or barley would be planted, the temperatures at the 5-cm depth averaged 8.8 and $12.2^{\circ} \mathrm{C}$, respectively (D. Huggins, personal communication). This indicates that $R$. oryzae would not be temperature limited, except during the winter or early spring. The optimum temperature for growth of $R$. oryzae in culture was 28 to $30^{\circ} \mathrm{C}(6,11)$ or $30^{\circ} \mathrm{C}(1)$. Ogoshi et al. (11) showed that isolates from the Pacific Northwest have a lower temperature optimum than rice isolates, indicating a low temperature ecotype. This discrepancy among studies may be due to the interaction of soil factors or possibly different temperature optima among isolates of $R$. oryzae, as demonstrated by Leiner et al. (6).

This is the first study to show a significant isolate-cultivar interaction with $R$. oryzae. Isolate 80042 was consistently the most virulent isolate on barley, and was originally isolated from spring barley. This isolate was intermediate in its virulence ranking compared with the other isolates on both cultivars of wheat. Isolate 801387 was the most virulent isolate for both cultivars of wheat, as measured by most parameters. This isolate also was isolated originally from spring barley, but was intermediate in ranking on barley, except when based on emergence and number of root tips, where it was the second most virulent isolate. Isolate 030109 was isolated from tall fescue and caused significant damage to both barley and wheat. $R$. $z e a e$, a species closely related to $R$. oryzae with the same teleomorph, was isolated from tall fescue in North Carolina (9). Two of the isolates that were tested by Martin and Lucas (9) were as virulent as R. solani, and caused severe disease on tall fescue (Festuca arundinaceae Schreb), perennial rye grass (Lolium perenne L.), and Kentucky blue grass (Poa pratensis L).

Exotic and native grasses are planted in large acreages of marginal and highly erodable land set aside as part of the Conservation Reserve Program of the Department of Agriculture, and could serve as a reservoir of Rhizoctonia inoculum when the land is put back into production. Kentucky blue grass also is grown for seed production in eastern Washington and northern Idaho, and farmers will often rotate back to cereals when the sod is no longer productive. If field burning is banned in these areas, rotations may be shorter, due to the shortened productive life of the Kentucky blue grass. Both isolates from pea, 030111 and 801344, caused significant damage to barley and wheat, although at an intermediate level. This indicates that $R$. oryzae may have a wider host range than members of the Poaceae family, and that rotation with broadleaf crops may not be an effective disease management tool for this pathogen. However, more work should be done to assess if the inoculum density and potential of $R$. oryzae increases or decreases during crop rotation or with time of planting. Broadleaf crops would have less root biomass in the top 10 to $15 \mathrm{~cm}$ of the soil, thus producing less inoculum.

Ability to detect differences in virulence may be a function of the number of isolates tested. Ogoshi et al. (11) reported no difference in virulence among three isolate tested, so they pooled their data. In the few studies that have included more than three isolates of $R$. oryzae, significant differences in virulence have been found among isolates on wheat (10) and barley (1). These findings have important implications for plant breeding strategies aimed at identifying and selecting tolerant or resistant germ plasm for use in cultivar enhancement. At present, no resistance to $R$. solani AG-8 has been detected among cultivars of spring wheat or spring barley commonly used in the Pacific Northwest (18), although some degree of tolerance or the ability to still produce reasonable yields has been observed with some spring barley cultivars (24). $R$. oryzae should be included in future germ plasm screenings, a number of isolates should be used, and these isolates should be selected for maximum virulence on a particular host. Further research is also needed to assess the dynamics of $R$. oryzae in direct-seeded or no-till systems, to determine whether lack of tillage exacerbates this disease, as it does for bare patch caused by $R$. solani AG-8 (23).

\section{ACKNOWLEDGMENTS}

We thank K. Adams for assistance with root scan analysis, K. Schroeder for assistance with 
statistical analysis, and J. Olmstead for assistance with experimental setup.

\section{LITERATURE CITED}

1. Burton, R. J., Coley-Smith, J. R., and Wareing, P. W. 1988. Rhizoctonia oryzae and $R$. solani associated with barley stunt disease in the United Kingdom. Trans. Br. Mycol. Soc. 91:409-417.

2. Cook, R. J., and Veseth, R. J. 1991. Wheat Health Management. American Phytopathological Society Press, St. Paul, MN.

3. Couch, H. B. 1995. Diseases of Turfgrass, 3rd ed. Kreiger Publishing Co., Malabar, FL.

4. Demirci, E. 1998. Rhizoctonia species and anastomosis groups isolated from barley and wheat in Erzurum, Turkey. Plant Pathol. 47:10-15.

5. Kidwell, K. K., Shelton, G. B., Morris, C. F., Line, R. F., Miller, B. C., Davis, M. A., and Konzak, C. F. 1999. Registration of 'Scarlet' wheat. Crop Sci. 39:1255.

6. Leiner, R. H., and Carling, D. E. 1994. Characterization of Waitea circinata (Rhizoctonia) isolated from agriculture soils in Alaska. Plant Dis. 78:385-388.

7. Martin, S. B., and Haygood, R. A. 1990. Characterization and pathogenicity of species of Rhizoctonia associated with centipedegrass and St. Augustinegrass in South Carolina. Plant Dis. 74:510-514

8. Martin, S. B., and Lucas, L. T. 1983. Pathogenicity of Rhizoctonia zeae on tall fescue and other turfgrasses. Plant Dis. 67:676-678.

9. Martin, S. B., and Lucas, L. T. 1984. Characterization and pathogenicity of Rhizoctonia spp. and binucleate Rhizoctonia-like fungi from turfgrass in North Carolina. Phytopathology 74:170-175.

10. Mazzola, M., Wong, O. T., and Cook, R. J. 1996. Virulence of Rhizoctonia oryzae and $R$. solani AG-8 on wheat and detection of $R$. oryzae in plant tissue by PCR. Phytopathology 86:354-360.

11. Ogoshi, A., Cook, R. J., and Bassett, E. N. 1990. Rhizoctonia species and anastomosis groups causing root rot of wheat and barley in the Pacific Northwest. Phytopathology 80:784-788.

12. Oniki, M., Ogoshi, A., Araki, T., Sakai, R., and Tanaka, S. 1985. The perfect state of Rhizoctonia oryzae and $R$. zeae, and the anastomosis groups of Waitea circinata. Trans. Mycol. Soc. Jpn. 26:189-198.

13. Paulitz, T. C. 2002. First report of Rhizoctonia oryzae on pea. Plant Dis. 86:442.

14. Paulitz, T. C., Zhang, H., and Cook, R. J. 2001. Spatial distribution of Rhizoctonia root rot in direct-seeded barley. (Abstr.) Phytopathology. 91:S70.

15. Raju, C. A. 1993. Waitea circinata causing damping-off in tobacco. Tobacco Res. 19:9295.

16. Ryker, T. C., and Gooch, F. S. 1938. Rhizoctonia sheath spot of rice. Phytopathology 28:233-246.

17. Smiley, R. W., and Uddin, W. 1993. Influence of soil temperature on Rhizoctonia root rot $(R$. solani AG-8 and $R$. oryzae) of winter wheat. Phytopathology 83:777-785.

18. Smith, J. D. 2001. Evaluation of spring cereal accessions and Triticum relatives for disease reaction to Rhizoctonia solani (K•hn) AG-8. M.S. thesis, Washington State University, Pullman.

19. Sprague, R. 1950. Diseases of Cereals and Grasses in North America. Ronald Press, New York.

20. Steele, R. G. D., Torrie, J. H., and Dickey, D. A. 1997. Principles and Procedures of Statistics: A Biometrical Approach, 3rd ed. McGraw-Hill, New York.

21. Voorhees, R. K. 1934. Sclerotial rot of corn caused by Rhizoctonia zeae, n. sp. Phytopathology 24:1290-1303.

22. Warcup, J. H., and Talbot, P. H. B. 1962 Ecology and identity of mycelia isolated from soil. Trans. Br. Mycol. Soc. 45:495-518.

23. Weller, D. M., Cook, R. J., MacNish, G. Bassett, E. N., Powelson, R. L., and Petersen, R. R. 1986. Rhizoctonia root rot of small grains favored by reduced tillage in the Pacific Northwest. Plant Dis. 70:70-73.

24. Wesselius, C. I. 2001. Stand establishment and performance characteristics of actual and simulated direct seeded spring barley genotypes under Rhizoctonia and Pythium disease pressure. M.S. thesis, Washington State University, Pullman.

25. Wong, D. H., Barbetti, M. J., and Sivasithamparam, K. 1985. Pathogenicity of Rhizoctonia spp. associated with root rots of subterranean clover. Trans. Br. Mycol. Soc. 85:156-158.

26. Wong, D. H., and Sivasithamparam, K. 1985. Rhizoctonia spp. associated with root rots of subterranean clover in Western Australia. Trans. Br. Mycol. Soc. 85:21-27. 